\title{
Antral Helicobacter pylori in patients with chronic renal failure
}

\author{
S Shousha, A H Arnaout, S H Abbas, R A Parkins
}

\begin{abstract}
Patients with chronic renal failure who were undergoing dialysis were recently shown to have a low prevalence of duodenal Helicobacter (Campylobacter) pylori colonisation in spite of a high incidence of gastric metaplasia. The prevalence of the organism in the gastric antrum of 50 similar patients was estimated and compared with that in a control group comprising 120 consecutive patients with no renal failure who were being investigated for a variety of symptoms and signs related to the upper alimentary tract. Seventeen of the patients with renal disease had upper gastrointestinal symptoms. The prevalence of antral $\boldsymbol{H}$ pylori was significantly less in patients with renal disease (12, $24 \%$ ) than in the control group $(51,42 \%)$, but was associated with a similar active chronic inflammatory reaction with prominent lymphoid follicles.

The prevalence of the bacteria in patients with renal disease was similar to that reported in normal volunteers, and was the same whether the patients had upper gastrointestinal symptoms or not. This low prevalence may be related to the wide variety of medication, including antibiotics, which these patients are prescribed during the course of their illness.
\end{abstract}

Colonisation of the duodenum with Helicobacter pylori (previously called Campylobacter pylori $\left.{ }^{1}\right)$ can occur only in the presence of gastric metaplasia. $^{23} \mathrm{We}$ have recently found that patients with chronic renal failure, who were undergoing dialysis, have a low prevalence of duodenal $H$ pylori colonisation in spite of the presence of a high incidence of gastric metaplasia. ${ }^{4}$ This prompted us to study, retrospectively, the prevalence of $H$ pylori in antral biopsy specimens from a similar group of patients and to compare it with the prevalence in a control group.

\section{Methods}

The study group included 50 patients with end stage chronic renal failure who were referred to the gastroenterology clinic for routine endoscopic examination before renal transplant surgery. All were receiving dialysis at home or in hospital. The control group included 120 patients with no renal failure seen during the same period who were being investigated for a variety of symptoms and signs related to the upper alimentary tract. Patients with gastric ulcers were not included in the study or control groups.
Upper gastrointestinal endoscopy was carried out with Olympus gastroscopes. Between one and six biopsy specimens (average $2 \cdot 2$ for both study and control groups) were taken from the antrum. The specimens were immediately fixed in neutral formalin and later routinely processed for histological examination.

Serial sections, varying in number between two and 32 (average $5 \cdot 6$ for the study group and 4.8 for the controls), were prepared from each biopsy specimen. Sections from all cases were stained with haematoxylin and eosin. A number of other sections were also stained with Warthin-Starry or modified Giemsa ${ }^{5}$ for the more specific demonstration of $H$ pylori, especially when examination of stained sections for the presence of these bacteria was inconclusive.

All sections were examined for evidence of chronic inflammation, judged by an increase of mononuclear inflammatory cells in the lamina propria, and active chronic inflammation, indicated by the presence of neutrophils as well as an excess of mononuclear cells in the mucosa. The presence or absence of lymphoid follicles, intestinal metaplasia, and $H$ pylori was then noted.

The significance of the results was assessed by the fourfold tables of the $\chi^{2}$ test, unless otherwise specified. Probabilities were calculated with one degree of freedom.

\section{Results}

PATIENTS

Twenty two patients $\left(44^{\circ}{ }_{0}\right)$ were male and 28 female. Their ages ranged between 26 and 78 years with a mean and standard deviation of $49.7(14.3)$ years. $H$ pylori was identified in 12 patients $\left(24^{\circ}{ }_{0}\right)$ (table 1$)$. These included eight men $\left(36^{\circ}{ }_{0}\right.$ of all male patients) and four women $\left(14^{\circ}{ }_{0}\right.$ of all female patients). The difference in prevalence between male and female patients was not significant $(\mathrm{p}<0 \cdot 1)$. The mean age and standard deviation was $54(14.3)$ years for infected patients and $48(14 \cdot 2)$ for uninfected patients. The difference in age between the two groups was not significant ( $\mathrm{p}=0.49$ with the Mann-Whitney U test).

Antral gastritis was present in 23 patients $\left(46^{\circ}{ }_{0}\right)$ (table 1$)$. This was active chronic in 17 and chronic in six. All 12 patients with $H$ pylori had active chronic antral gastritis. Eleven uninfected patients $\left(29^{\circ}\right.$ o $)$ had inflammation without bacteria (table 2). Thus the organism was present in 12 out of $23(52 \%)$ of all patients with antral gastritis and in 12 out of $17(71 \%$ ) of those with active chronic inflammation. The difference in prevalence of inflammation be- 
Table 1 Histological findings in antral biopsy specimens of patients with chronic renal failure and control group (endoscopic population)

\begin{tabular}{|c|c|c|c|}
\hline & \multicolumn{2}{|l|}{ Patients } & \multirow{2}{*}{$\begin{array}{l}\text { Control } \\
\text { group } \\
(n=120)\end{array}$} \\
\hline & $\begin{array}{l}\text { Total } \\
(n=50)\end{array}$ & $\begin{array}{l}\text { Symptomatic } \\
(n=17)\end{array}$ & \\
\hline $\begin{array}{l}\text { H pylori }\left(\mathrm{No} /{ }^{\circ}{ }^{\circ}\right) \\
\text { Antral gastritis } \\
\text { Active chronic } \\
\text { Chronic } \\
\text { Lymphoid follicles } \\
\text { Intestinal metaplasia }\end{array}$ & $\begin{array}{r}12(24) \\
23(46) \\
17(34) \\
6(12) \\
14(28) \\
7(14)\end{array}$ & $\begin{array}{l}3(18) \\
8(47) \\
6(35) \\
2(12) \\
3(18) \\
3(18)\end{array}$ & $\begin{array}{l}51(42) \\
73(61) \\
58(48) \\
15(12) \\
37(31) \\
10(8)\end{array}$ \\
\hline
\end{tabular}

tween infected and uninfected patients was significant $(\mathrm{p}<0.001)$.

Lymphoid follicles were present in $11(92 \%)$ cases with $H$ pylori and in three (8\%) other cases (table 2), a highly significant difference $(\mathrm{p}<0.001)$. In general, lymphoid follicles were seen in 11 out of $17(65 \%)$ patients with chronic active inflammation and two out of six $(33 \%)$ patients with chronic inflammation The difference between these two groups was not significant $(p<0 \cdot 5)$. The follicles were not seen in any case without inflammation. Of all 14 cases with lymphoid follicles, $11(79 \%)$ had $H$ pylori.

Focal intestinal metaplasia was seen in seven out of the $50(14 \%)$ patients: four $(33 \%)$ with $H$ pylori and three $(8 \%$ ) without (table 2$)$. The difference was significant $(p<0.05)$. The bacteria, when present, were always associated with the non-metaplastic areas.

Only seventeen (34\%) patients, eight men and nine women, had upper gastrointestinal symptoms at the time of examination (table 1 ). $H$ pylori was identified in only three $(18 \%)$ of these patients, compared with eight $(27 \%)$ out of 30 known asymptomatic patients. The presence or absence of symptoms in the remaining three patients, including one with $H$ pylori, was not known at the time of the biopsy. The difference in prevalence of $H$ pylori, antral gastritis, lymphoid follicles and intestinal metaplasia between the symptomatic and asymptomatic groups was not significant.

\section{CONTROL GROUP}

Sixty seven $(56 \%)$ patients were male and 53 were female. Their ages ranged between 20 and 84 years with a mean of 52.6 years $( \pm 18 \cdot 5) . H$ pylori was identified in 51 cases $(42 \%)$ (table 1 ), including 31 men ( $46 \%$ of all male patients) and 20 women ( $38 \%$ of all female patients). The difference in prevalence of bacteria between the two sexes was not significant. The mean age and standard deviation was $53(18 \cdot 6)$ years for infected patients and $52(18.6)$ for uninfected patients (NS, $p=0.5$, Mann-Whitney U test).

Antral gastritis was present, histologically, in all 51 infected patients (table 2). The inflammation was active chronic in $46(90 \%)$ and

Table 2 Comparison between $H$ pylori positive and negative biopsy specimens in patients and control group

\begin{tabular}{|c|c|c|c|c|}
\hline & \multicolumn{2}{|l|}{ Patients } & \multicolumn{2}{|c|}{ Control group } \\
\hline & $\begin{array}{l}\text { Positive } \\
(n=12)\end{array}$ & $\begin{array}{l}\text { Negative } \\
(n=38)\end{array}$ & $\begin{array}{l}\text { Positive } \\
(n=51)\end{array}$ & $\begin{array}{c}\text { Negative } \\
(n=69)\end{array}$ \\
\hline $\begin{array}{l}\text { Antral gastritis }(\mathrm{No} / \%) \\
\text { Active chronic } \\
\text { Chronic } \\
\text { Lymphoid follicles } \\
\text { Intestinal metaplasia }\end{array}$ & $\begin{array}{c}12(100) \\
12(100) \\
0 \\
11(92) \\
4(33)\end{array}$ & $\begin{array}{l}11(29) \\
5(13) \\
6(16) \\
3(8) \\
3(8)\end{array}$ & $\begin{array}{l}51(100) \\
46(90) \\
5(10) \\
34(67) \\
5(10)\end{array}$ & $\begin{array}{c}22(32) \\
12(17) \\
10(14) \\
13(19) \\
5(7)\end{array}$ \\
\hline
\end{tabular}

chronic in five. On the other hand, $22(32 \%)$ uninfected patients had antral gastritis which was active chronic in 12 and chronic in 10 Thus $H$ pylori was present in 51 out of 73 $(70 \%)$ of all patients with antral gastritis and in 46 out of $58(79 \%)$ of patients with active chronic antral gastritis. The difference in prevalence of inflammation between infected and uninfected patients was highly significant $(\mathrm{p}<0.001)$.

Thirty four $(67 \%)$ cases with $H$ pylori had mucosal lymphoid follicles. In contrast, only 13 $(19 \%)$ cases without bacteria had lymphoid follicles (table 2). The difference between these two groups was significant $(\mathrm{p}<0.001)$. The prevalence of $H$ pylori in biopsy specimens with lymphoid follicles was $72 \%$ (34 cases out of 47).

Intestinal metaplasia was present in 10 out of the $120(8 \%)$ patients, five $(10 \%)$ with, and five $(7 \%$ ) without organisms (table 2). The difference in prevalence between the two groups was not significant.

COMPARISON BETWEEN PATIENT AND CONTROL GROUPS

There was no significant difference in the mean and standard deviation of patients' ages between the two groups ( $p=0 \cdot 5$, Mann-Whitney $\mathrm{U}$ test). The difference in the prevalence of antral $H$ pylori colonisation in the two groups $(24 \%$ for chronic renal failure patients and $42 \%$ for control patients (table 1 ) was significant $(\mathrm{p}<0.05)$. The difference was also significant when only the symptomatic renal patients were compared with the controls $(18 \%$ $v 42.5 \%, \mathrm{p}<0.05)$.

The difference in the prevalence of antral gastritis in the two groups $(46 \% v 61 \%)$ was significant ( $p<0.05)$, but, although the prevalence of chronic, non-active, antral gastritis was similar in the two groups $(12 \%$ each) (table 1), the difference in the prevalence of active chronic inflammation $(34 \% v 48 \%)$ did not reach significance ( $p<0 \cdot 1$, respectively).

There were no significant differences between the prevalence of lymphoid follicles and intestinal metaplasia in the two groups $(28 \% v$ $31 \%$, and $14 \% v 8 \%$, respectively; $\mathrm{p}<0.5)$.

\section{Discussion}

Our findings suggest that patients with chronic renal failure who are undergoing dialysis, irrespective of whether they have upper gastrointestinal symptoms or not, have a prevalence of antral $H$ pylori colonisation similar to that reported in normal younger volunteers in spite of the fact that the prevalence is known to increase with age. ${ }^{67}$ This prevalence is also less than that usually seen in endoscopic populations composed of patients referred to the endoscopy clinic with signs and symptoms related to the upper gastrointestinal tract. Thus the noted $24 \%$ overall prevalence of $H$ pylori in our renal patients is comparable with the 11$27 \%$ prevalence reported in normal asymptomatic volunteers with a mean age varying between 29 and 38 years, ${ }^{7-10}$ but is significantly less than the $42 \%$ prevalence found in our control endoscopy population whose prevalence fell into the lower end of the 42$64 \%$ range reported in other studies of similar patients. ${ }^{1-16}$ 
The low prevalence of antral $H$ pylori in the patients with renal disease and upper gastrointestinal symptoms $(18 \%$, table 1$)$, suggests that these patients are probably less commonly infected with $H$ pylori than the general population. This has also been noted before in the duodenum. ${ }^{4}$ The reason is not obvious, but could be related to the wide variety of medications which these patients are prescribed during the course of their illness. A list of these drugs proved difficult to compile for each individual patient, but repeated courses of antibiotics are often used. It is unlikely that the reported low prevalence is due to low sensitivity of histological detection in patients with a low bacterial load as in almost all our cases serial sections of multiple antral biopsy specimens were examined, and this has been shown to be one of the most sensitive methods of identifying the organisms. ${ }^{15}$ Biopsy specimens from patients with renal disease and controls were treated in the same way, and any factor that might have affected the results of one group would have had the same effect on the other.

The $46 \%$ prevalence of antral gastritis in the patients studied is within the $41-46 \%$ range previously reported in similar series, ${ }^{17-19}$ and the $34 \%$ prevalence of active chronic inflammation is not so different from the $26 \%$ prevalence reported by Margolis et al. ${ }^{17}$ Both these values, which are significantly less than those seen in endoscopic populations, did not vary with the presence or absence of upper gastrointestinal symptoms (table 1 ). This suggests that in most patients such symptoms are not related to the presence of gastritis and in particular are not caused by $H$ pylori colonisation. This is further supported by the absence of upper gastrointestinal symptoms in about a quarter of our patients with renal failure who harboured the organism (table 1).

Our study also confirms the close association between the presence of $H$ pylori and the presence of both active chronic inflammation ${ }^{910}$ and prominent lymphoid follicles ${ }^{20}$ in the antral mucosa of patients without renal disease, and extends these observations to those with (table 2). Unlike Wyatt and Rathbone, ${ }^{20}$ however, lymphoid follicles were seen, although much less commonly, in the absence of identifiable $H$ pylori in both groups (table 2). Our $92 \%$ and $67 \%$ prevalences of lymphoid follicles in infected renal and non-renal patients, respectively, were much higher than the $27.4 \%$ prevalence reported by Wyatt and Rathbone, which they seem to have correctly predicted to be an underestimate..$^{20}$

An unexpected finding in this study was the higher prevalence of intestinal metaplasia in patients with renal disease and $H$ pylori, compared with those without (table 2). The number of cases with intestinal metaplasia in each group is too small, however, to allow any reasonable conclusions to be drawn and a more detailed study concerning this observation may be worth undertaking. It must be added here that the intestinal metaplasia, when present, was always patchy, and that the bacteria were seen only in relation to non-metaplastic cells.

It is concluded that patients undergoing dialysis for chronic renal failure, irrespective of whether they have upper gastrointestinal symptoms or not, have a prevalence of antral $H$ pylori infection and gastritis which is no different from that reported in younger healthy volunteers. The bacteria may be present in these patients without producing symptoms, but usually gastrointestinal symptoms are present in the absence of bacteria. Microscopically, the presence of bacteria is almost always associated with active chronic inflammation and prominent mucosal lymphoid follicles, but both histological features are occasionally seen in the absence of the organisms.

We thank Dr M Barrett for helping with the statistical calculations.

Part of this work was presented, in an abstract form, in the second meeting of the European Campylobacter pylori study group which was held in Ulm, West Germany, October 12-14, group
1989.

1 Goodwin CS, Armstrong JA, Chilvers T, et al. Transfer of Campylobacter pylori and Campylobacter mustelae to Helicobacter gen. nov. as Helicobacter pylori comb. nov. and Helicobacter mustelae comb. nov., respectively. Int System Bact 1989;39:397-405.

2 Johnston BJ, Reed PI, Ali MH. Campylobacter like organisms in duodenal and antral endoscopic biopsies: relationisms in duodenal and antral endoscopic biops

3 Wyatt JI, Rathbone BJ, Dixon MF, Heatley RV. Campylobacter pyloridis and acid induced gastric metaplasia in the pathogenesis of duodenitis. J Clin Pathol 1987;40:841-8.

4 Shousha S, Keen C, Parkins RA. Gastric metaplasia and Campylobacter pylori infection of duodenum in patients with chronic renal failure. $J$ Clin Pathol 1989, 42:348-51.

5 Gray SF, Wyatt JI, Rathbone BJ. Simplified techniques for identifying Campylobacter pyloridis. J Clin Pathol 1986; 39:1279.

6 Perez-Perez GI, Dworkin BM, Chodos JE, Blaser MJ. Campylobacter pylori antibodies in humans. Ann Intern Med 1988;109:11-17.

7 Gregson DB, Low DE, Cohen MM, et al. The prevalence of Campylobacter pylori gastritis among asymptomatic adults. Can Med Assoc J 1989;140:1449-53.

8 Bathel JS, Westblom TU, Havey AD, Gonzalez F, Everett ED. Gastritis and Campylobacter pylori in healthy, asymptomatic volunteers. Arch Intern Med 1988, 148:1149-51.

9 Rauws EAJ, Langenberg W, Houthoff HJ, Zanen HC Tytgat GNJ. Campylobacter pyloridis-associated chronic active antral gastritis. A prospective study of its prevalence and the effects of antibacterial and antiulcer treatment. and the effects of antibacterial
Gastroenterology 1988;94:33-40.

10 Peterson WL, Lee E, Feldman M. Relationship between Campylobacter pylori and gastritis in healthy humans after administration of placebo or indomethacin. Gastroenterology 1988;95:1185-97.

11 Marshall BJ, Warren JR. Unidentified curved bacilli in the stomach of patients with gastritis and peptic ulceration. Lancet 1984; i:1311-15.

12 Rollason TP, Stone J, Rhodes JM. Spiral organisms in endoscopic biopsies of the human stomach. J Clin Pathol 1984;37:23-6.

13 Jones DM, Lessells AM, Eldridge J. Campylobacter like organisms on the gastric mucosa: culture, histological, and serological studies. J Clin Pathol 1984;37:1002-6.

14 Musgrove C, Bolton FJ, Krypczyk AM, et al. Campylobacter pylori: clinical, histological, and serological studies. $J$ Clin Pathol 1988;41:1316-21.

15 Morris A, Ali MR, Brown P, Lane M, Patton K. Campylobacter pylori infection in biopsy specimens of gastric antrum: laboratory diagnosis and estimation of sampling error. J Clin Pathol 1989;42:727-32.

16 Bayerdorffer E, Oertel J, Lehn N, et al. Topographic association between active gastritis and Campylobacter pylori colonisation. J Clin Pathol 1989;42:834-9.

17 Margolis DM, Saylor JL, Geisse G, DeSchryverKecskemeti K, Harter HR, Zuckerman GR. Upper gastrointestinal disease in chronic renal failure. A pros-

pective evaluation. Arch Intern Med 1978;138:1214-17.
Franzin G, Musola R, Mencarelli R. Morphological changes of the gastroduodenal mucosa in regular dialysis uraemic patients. Histopathology 1982;6:429-37.

19 Paimela H, Stenman S, Kekki M, Sipponen P, Tallgren LG, Scheinin TM. Chronic gastritis and gastric acid secretion in uraemic and renal transplant patients. Hepato-gastroenterol 1985;32:15-19.

20 Wyatt JI, Rathbone BJ. Immune response of the gastric mucosa to Campylobacter pylori. Scand J Gastroenterol 1988;23 (suppl 142):44-9. 